\title{
A STUDY TO EVALUATE THE ADVERSE REACTION OF TETANUS VACCINE (ADSORBED) IN HEALTHY INDIAN ADULTS
}

\author{
Bongu Srinivasa Rao1, A. Gopal Rao², Sharath Babu Naik Z
}

${ }_{1}^{1}$ Associate Professor, Department of Medicine, RIMS, Srikakulam.

${ }^{2}$ Associate Professor, Department of Medicine, RIMS, Srikakulam.

${ }^{3}$ Assistant Professor, Department of Community Medicine, RIMS, Srikakulam.

\section{BACKGROUND}

ABSTRACT

Tetanus disease is one of the most dramatic and globally prevalent diseases of humans and vertebrate animals and has been reported for over 24 centuries. The manifestation of the disease, spastic paralysis, is caused by the second most poisonous substance known as the tetanus toxin. According to the World Health Organisation, India had reported 70,335 cases of Tetanus in the period from 2000 - 2015, of these 17,025 cases were neonatal tetanus. Serological surveys have demonstrated an increasing proportion of patients with inadequate immunity as age increases: $49 \%-66 \%$ of patients over 60 years had antibody levels below the protective level.[4-6]

\section{MATERIALS AND METHODS}

This was a single arm, uncontrolled clinical trial study to evaluate the adverse events following Tetanus Vaccine (Adsorbed) in healthy adult subjects. Total 39 healthy individuals consented for the study and after exclusion criteria all eligible were enrolled into the study, i.e. a total of 34 healthy adult subjects aged 18 to 45 years were enrolled into the study. All selected individuals were admitted as IP for evaluation of the adverse reactions for 3 days and follow-up till 28 days. Single dose of the Tetanus Vaccine (Adsorbed) $0.5 \mathrm{~mL}$ was administered as deep intramuscular injection into the deltoid region. Observation period was 28 days after vaccination. There were no antibody estimation done in this trial. Local and systemic reactions were collected for 28 days following injection using Diary Card (i.e. Day 0 to Day 28). All AEs, SAEs and AEs that lead to withdrawal from the study and related prescription vaccines were collected for the entire study period.

\section{RESULTS}

The study population consisted of 34 healthy adult subjects aged between 18 and 45 years. All subjects received the study vaccine and hence the safety population consisted of all $(100 \%)$ vaccinated subjects.

\section{CONCLUSION}

This was a single arm study designed to evaluate the safety and tolerability of Tetanus Vaccine (Adsorbed) in healthy adult subjects. A total of 34 healthy adult subjects aged 21 to 44 years were enrolled into the study. A total of 39 subjects were screened for the study. Of these, 34 subjects received the study vaccine.

\section{KEYWORDS}

Tetanus Vaccine, Antibody Estimation, Intramuscular Injection, Systemic Reaction, Safety Analysis.

HOW TO CITE THIS ARTICLE: Rao BS, Rao AG, Naik SBZ. A study to evaluate the adverse reaction of tetanus vaccine (adsorbed) in healthy Indian adults. J. Evolution Med. Dent. Sci. 2018;7(04):403-406, DOI: 10.14260/jemds/2018/90

\section{BACKGROUND}

Tetanus disease is one of the most dramatic and globally prevalent diseases of humans and vertebrate animals and has been reported for over 24 centuries. The manifestation of the disease, spastic paralysis, is caused by the second most poisonous substance known as the tetanus toxin with a human lethal dose of $1 \mathrm{ng} / \mathrm{kg}$. Fortunately, this disease is successfully controlled through immunisation with tetanus toxoid. Nevertheless, according to the World Health Organisation data, India had reported 70,335 cases of Tetanus in the period $2000-2015$. Of these, 17,025 cases

'Financial or Other Competing Interest': None.

Submission 13-11-2017, Peer Review 20-12-2017,

Acceptance 26-12-2017, Published 20-01-2018.

Corresponding Author:

Dr. Bongu Srinivasa Rao,

Associate Professor,

Department of General Medicine,

RIMS, Srikakulam.

E-mail: bhavyabongu@gmail.com

DOI: $10.14260 /$ jemds $/ 2018 / 90$

\section{(c) (i) $(9)$}

were neonatal tetanus. The causative agent of tetanus disease is Clostridium tetani, an anaerobic spore-forming bacterium, whose natural habitat is soil, dust and intestinal tracts of various animals.[1-2] Tetanus is now a rare disease in the developed world. However, it remains an important cause of death worldwide and is associated with a high case mortality, particularly in the developing world. As per 2013 World Health Organisation data, there are 49,000 newborns who died due to Neonatal Tetanus.[3] Serological surveys have demonstrated an increasing proportion of patients with inadequate immunity as age increases: $49 \%$ - $66 \%$ of patients over 60 years had antibody levels below the protective level.[4-6] Some have never been vaccinated, while others have lost their immunity.[7] Tetanus is an important endemic infection in India. Prior to the national immunisation program, an estimated 3.5 lakh children died annually due to neonatal tetanus. As per WHO, in India 2,268 tetanus cases were reported in the year 2015 (WHO- Immunisation surveillance, assessment and monitoring- Data statistics and graphics).[1]

Tetanus Antigen- Clostridium tetani, an obligate anaerobic gram-positive bacillus causes tetanus. This 
bacterium is non-encapsulated and forms spores, which are resistant to heat, desiccation and disinfectants. The spores are ubiquitous and are found in soil, house dust, animal intestines and human faeces. Spores that gain entry can persist in normal tissue for months to years. Under anaerobic conditions, these spores geminate and elaborate tetanospasmin and tetanolysin. Tetanolysin is not believed to be of any significance in the clinical course of tetanus. Tetanospasmin that is released by the maturing bacilli is distributed via the lymphatic and vascular circulations to the end plates of all nerves. Tetanospasmin then enters the nervous system peripherally at the myoneural junction and is transported centripetally into neurons of the central nervous system (CNS). These neurons become incapable of neurotransmitter release. The neurons, which release gamma-aminobutyric acid (GABA) and glycine, the major inhibitory neurotransmitters are particularly sensitive to tetanospasmin, leading to failure of inhibition of motor reflex responses to sensory stimulation. This results in generalised contractions of the agonist and antagonist musculature characteristic of a tetanic spasm. The shortest peripheral nerves are the shortest peripheral nerves, they are the first to deliver the toxin to the CNS which leads to the early symptoms of facial distortion and back and neck stiffness. Once the toxin becomes fixed to neurons, it cannot be neutralised with antitoxin. Recovery of nerve function from tetanus toxins require sprouting of new nerve terminals and formation of new synapses.

\section{Aim of Study \\ To Evaluate the Safety and Tolerability of the Tetanus Vaccine (Adsorbed) \\ 1. To evaluate solicited local and general adverse events following tetanus vaccine. \\ 2. To identify system organ classification of symptoms following Tetanus vaccine.}

\section{MATERIALS AND METHODS \\ Design}

This was a single arm, uncontrolled clinical trial study to the adverse reactions following Tetanus Vaccine (Adsorbed) I.P. in healthy adult subjects. Primary endpoint of the study was to observe occurrence of solicited local and general adverse events from 30 minutes to 3 days (Day 0 - 3) followup period after vaccination and occurrence of unsolicited symptoms during the 28 days (Day 0 - 28) follow-up period after vaccination and occurrence of serious adverse events (SAEs) throughout the study.

\section{Study Period}

28 days.

\section{Sampling}

Convenient sampling method was used for the selection of study subjects. All eligible subjects among the enrolled received single dose of the Tetanus vaccine (Adsorbed), 0.5 $\mathrm{mL}$ was administered subcutaneously, i.e. $100 \%$ of the eligible study subjects among enrolled were included in this study. Total study and observation period was 28 days after vaccination.

Local and systemic reactions were collected for 28 days following injection. All AEs, SAEs and AEs that led to withdrawal from the study and related prescription vaccines were collected for the entire study period using Diary card.

\section{Sample Size}

Convenience sample size was used, as there are no statistically powered hypotheses in this study, a study sample size $(\mathrm{N}=33)$ provide a probability of approximately $95 \%$ of observing any $\mathrm{AE}$ having a true incidence of $3 \%$. Assuming a dropout rate of approximately 10\%, a total of 30 evaluable subjects was anticipated to complete the study and the present study $\mathrm{n}=34$.

\section{Eligibility Criteria \\ Inclusion Criteria}

1. Healthy Adults of 18 - 45 years of age who gave written informed consent prior to the study entry.

2. Willingness to adhere to the study requirements.

3. Subjects with good health as determined by:

- Medical history.

- Physical examination.

- Clinical judgement of the investigator.

- Clinical laboratory examination (subjects with clinically acceptable range during baseline screening).

\section{Exclusion Criteria}

1. Administration of immunoglobulin or any blood products since birth.

2. Use of any investigational or unregistered drug or vaccine other than the study vaccine during the study period or within 30 days preceding the study vaccination.

3. Subjects who had received any vaccines 6 months prior to study entry.

4. Previous evidence of Tetanus.

5. History of allergic disease or reaction likely to be exacerbated by any component of the vaccine including allergy to antibiotics.

6. Major congenital or hereditary immunodeficiency.

Hence, after applying the inclusion and exclusion criteria 34 of 39 study subjects were enrolled into the study, i.e. $\mathrm{n}=34$.

\section{Statistical Methods}

The analysis of adverse reactions were performed on the study population. Reported solicited and unsolicited adverse events were summarised using frequencies and percentages, by event severity and event relationship to the study vaccine. Any serious adverse events were listed. Frequency and percentage of subjects with at least one adverse event after vaccination and during the study period were calculated. The adverse events were calculated at the end of study. 
RESULTS

\begin{tabular}{|c|c|c|}
\hline \multicolumn{2}{|l|}{ Subject Category } & $\begin{array}{c}\text { Tetanus Vaccine } \\
(n=34) \text { n }(\%)\end{array}$ \\
\hline \multicolumn{2}{|c|}{ Number (\%) of Subjects with Solicited AE } & $5(14.7)$ \\
\hline \multicolumn{2}{|l|}{ Mild } & $3(8.8)$ \\
\hline \multicolumn{2}{|l|}{ Moderate } & $2(5.8)$ \\
\hline \multicolumn{2}{|l|}{ Severe } & - \\
\hline \multicolumn{2}{|c|}{ Number (\%) of Subjects with Local AE } & $4(11.7)$ \\
\hline \multicolumn{2}{|l|}{ Mild } & $3(8.8)$ \\
\hline \multicolumn{2}{|l|}{ Moderate } & $1(2.9)$ \\
\hline \multicolumn{2}{|l|}{ Severe } & - \\
\hline \multicolumn{2}{|c|}{ Number (\%) of Subjects with Systemic AE } & $1(2.9)$ \\
\hline \multicolumn{2}{|c|}{ Mild } & - \\
\hline \multicolumn{2}{|l|}{ Moderate } & $1(2.9)$ \\
\hline \multicolumn{2}{|l|}{ Severe } & - \\
\hline \multicolumn{2}{|c|}{ Relationship with Study Vaccine } & $5(14.7)$ \\
\hline \multicolumn{2}{|l|}{ Not Related } & - \\
\hline \multicolumn{2}{|c|}{ Very Likely Related } & $4(14.7)$ \\
\hline \multicolumn{2}{|l|}{ Possibly Related } & $1(2.9)$ \\
\hline \multicolumn{2}{|c|}{$\begin{array}{l}\text { No. of subjects discontinued due to } \\
\text { solicited AE }\end{array}$} & - \\
\hline \multicolumn{3}{|c|}{$\begin{array}{c}\text { Table 1. Overview of Solicited Adverse } \\
\text { Events }\end{array}$} \\
\hline Subject Category & \multicolumn{2}{|c|}{$\begin{array}{c}\text { Tetanus Vaccine } \\
(n=34) n(\%)\end{array}$} \\
\hline $\begin{array}{c}\text { Number (\%) of Subjects with } \\
\text { an AE }\end{array}$ & \multicolumn{2}{|c|}{$8(23.5)$} \\
\hline Mild AE & \multicolumn{2}{|c|}{$6(17.6)$} \\
\hline Moderate AE & \multicolumn{2}{|r|}{$2(5.8)$} \\
\hline Severe AE & & - \\
\hline \multicolumn{3}{|l|}{ Vaccine Relationship to $\mathrm{AE}$} \\
\hline Not related & \multicolumn{2}{|r|}{$3(8.8)$} \\
\hline Very likely related & \multicolumn{2}{|c|}{$5(14.7)$} \\
\hline Probably related & \multicolumn{2}{|r|}{-} \\
\hline $\begin{array}{l}\text { No. of subjects discontinued } \\
\text { due to unsolicited } \mathrm{AE}\end{array}$ & \multicolumn{2}{|r|}{ - } \\
\hline
\end{tabular}

\begin{tabular}{|c|c|}
\hline $\begin{array}{c}\text { Reactions/ Preferred } \\
\text { Term }\end{array}$ & $\begin{array}{c}\text { Tetanus Vaccine (n= 34) n } \\
\text { (\%) }\end{array}$ \\
\hline $\begin{array}{c}\text { Number of Subjects with at } \\
\text { least one Solicited AE }\end{array}$ & $5(14.7)$ \\
\hline Local AE & $2(5.8)$ \\
\hline Pain at injection site & $2(5.8)$ \\
\hline Itching & - \\
\hline Erythema & - \\
\hline Systemic AE & - \\
\hline Irritability & - \\
\hline Drowsiness & $1(2.9)$ \\
\hline Vomiting & Treatment \\
\hline \multicolumn{2}{|c|}{ Table 3. Solicited Adverse Events by SOC, PT and } \\
\hline
\end{tabular}

\begin{tabular}{|c|c|c|c|c|}
\hline & \multicolumn{4}{|c|}{ Tetanus Vaccine (n= 34) n (\%) } \\
\hline $\begin{array}{c}\text { Reactions/ } \\
\text { Preferred Term }\end{array}$ & None & Mild & Moderate & Severe \\
\hline $\begin{array}{c}\text { Number of } \\
\text { Subjects with } \\
\text { Solicited AE }\end{array}$ & - & $3(8.8)$ & $2(5.8)$ & - \\
\hline Local AE & & & & \\
\hline Pain at injection & - & $1(2.9)$ & $1(2.9)$ & - \\
\hline
\end{tabular}

\begin{tabular}{|c|c|c|c|c|}
\hline site & & & & \\
\hline Itching & - & $2(5.8)$ & - & - \\
\hline Erythema & - & - & - & - \\
\hline Systemic AE & & & & \\
\hline Irritability & - & - & - & - \\
\hline Drowsiness & - & - & - & - \\
\hline Vomiting & - & - & - & - \\
\hline Fever & - & - & $1(2.9)$ & - \\
\hline Table 4. Solicited Adverse Events by SOC, PT, Treatment \\
and Severity \\
\hline
\end{tabular}

\begin{tabular}{|c|c|c|c|c|c|c|}
\hline \multirow[b]{2}{*}{ 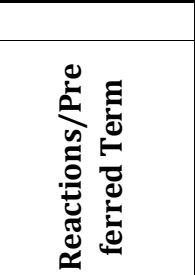 } & \multicolumn{6}{|c|}{ Tetanus Vaccine $(n=34)$ n (\%) } \\
\hline & 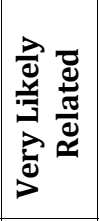 & 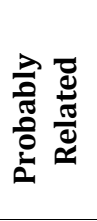 & 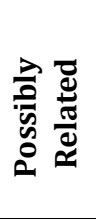 & 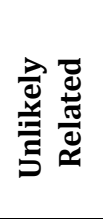 & 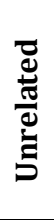 & 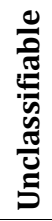 \\
\hline $\begin{array}{c}\text { Number of } \\
\text { Subjects with } \\
\text { Solicited AE }\end{array}$ & $\begin{array}{c}4 \\
(11.7)\end{array}$ & - & $\begin{array}{c}1 \\
(2.9)\end{array}$ & - & - & - \\
\hline $\begin{array}{l}\text { Local } \\
\text { reactions }\end{array}$ & & & & & & \\
\hline $\begin{array}{c}\text { Pain at } \\
\text { injection site }\end{array}$ & $\begin{array}{c}2 \\
(5.8)\end{array}$ & - & - & - & - & - \\
\hline Itching & $\begin{array}{c}2 \\
(5.8)\end{array}$ & - & - & - & - & - \\
\hline Erythema & - & - & - & - & - & - \\
\hline $\begin{array}{l}\text { Systemic } \\
\text { reactions }\end{array}$ & & & & & & \\
\hline Irritability & - & - & - & - & - & - \\
\hline Drowsiness & - & - & - & - & - & - \\
\hline Vomiting & - & - & - & - & - & - \\
\hline Fever & - & - & $\begin{array}{c}1 \\
(2.9)\end{array}$ & - & - & - \\
\hline
\end{tabular}

\begin{tabular}{|c|c|}
\hline Soc/ Preferred Term & $\begin{array}{c}\text { Tetanus Vaccine } \\
(\mathbf{n = 3 4 )} \mathbf{n}(\mathbf{\%})\end{array}$ \\
\hline $\begin{array}{c}\text { General disorders and } \\
\text { administration site conditions }\end{array}$ & $6(17.6)$ \\
\hline Redness & $2(5.8)$ \\
\hline $\begin{array}{c}\text { Inability/ functional incapacity } \\
\text { to lift the arm }\end{array}$ & $3(8.8)$ \\
\hline Fever* & $1(2.9)$ \\
\hline Infections and Infestations & $1(2.9)$ \\
\hline Cold $^{*}$ & $1(2.9)$ \\
\hline Nervous system disorder & $1(2.9)$ \\
\hline Headache* & $1(2.9)$ \\
\hline
\end{tabular}

*- Fever, cold and headache were reported after 9 - 13 days of vaccination.

\begin{tabular}{|c|c|c|c|}
\hline SOC/ Preferred Term & \multicolumn{4}{|c|}{ Tetanus Vaccine (n= 34) n (\%) } \\
\hline & Mild & Moderate & Severe \\
\hline $\begin{array}{c}\text { Number of Subjects with } \\
\text { Unsolicited AE }\end{array}$ & $6(17.6)$ & $2(5.8)$ & - \\
\hline $\begin{array}{c}\text { General disorders } \\
\text { and administration } \\
\text { site conditions }\end{array}$ & $5(14.7)$ & $1(2.9)$ & - \\
\hline Redness & $2(5.8)$ & - & - \\
\hline Inability/ & & & \\
\hline
\end{tabular}




\begin{tabular}{|c|c|c|c|}
\hline $\begin{array}{c}\text { Functional } \\
\text { incapacity to lift the } \\
\text { arm }\end{array}$ & $3(8.8)$ & - & - \\
\hline Fever* & - & $1(2.9)$ & \\
\hline $\begin{array}{c}\text { Infections and } \\
\text { Infestations }\end{array}$ & - & $1(2.9)$ & - \\
\hline Cold* & - & $1(2.9)$ & - \\
\hline Nervous system disorder & $1(2.9)$ & - & - \\
\hline Headache* & $1(2.9)$ & - & - \\
\hline Table 6. Unsolicited Adverse Events by SOC, PT and \\
Severity \\
\hline
\end{tabular}

*- Fever, cold and headache were reported after 9 - 13 days of vaccination.

\section{DISCUSSION}

The conquest of infectious diseases demands either a means of effective prevention or total eradication of the causative agent. In tetanus only, the first proposition can be entertained.

The objective of the present study was to assess the safety and tolerability of Tetanus Vaccine (Adsorbed) manufactured by Seasons Biologicals Pvt. Ltd. in healthy adult subjects.

This was a single arm study designed to evaluate the safety and tolerability of Tetanus Vaccine (Adsorbed) in healthy adult subjects. A total of 34 healthy adult subjects aged 21 to 44 years were enrolled into the study. A total of 39 subjects were screened for the study. Of these, 34 subjects received the study vaccine.

Primary endpoint of the study was to evaluate the safety and tolerability of the Tetanus Vaccine (Adsorbed). Safety end point was to observe occurrence of solicited local and general adverse events from 30 minutes to 3 days (Day 0 3 ) follow-up period after vaccination and occurrence of unsolicited symptoms during the 28 days (Day 0 - 28) follow-up period after vaccination and occurrence of serious adverse events (SAEs) throughout the study.

None of the subjects reported any vaccine related reactions in 30 minutes post-dose.

Five (14.7\%) subjects reported at least one solicited AE during the study period. Pain at injection site (5.8\%) and itching $(5.8 \%)$ were the commonly reported AE. Eight (23.5\%) subjects reported at least one unsolicited AEs. The most commonly reported unsolicited AEs by preferred term is Inability/ Functional incapacity to lift the arm (3 subjects, $8.8 \%$ ) followed by redness ( 2 subjects, $5.8 \%$ ).

Fever, cold and headache were reported by one (1, $2.9 \%$ ) subject each after 9 - 13 days of vaccination. These events were not related to the study vaccine as per the investigator opinion.

All the reported AEs were mild or moderate in nature and were likely or unrelated to the study vaccine. The safety profile of the Tetanus Toxoid (Adsorbed) produced by Seasons Biologicals Pvt. Ltd. is similar to what has been reported in literature.[8]
No serious adverse events (SAE) were occurred in this study.

\section{CONCLUSION}

The Administered Vaccine was Well Tolerated by Subjects in the Study. The Results are Summarised Below-

1. None of the subjects reported any vaccine related reactions within 30 minutes post-dose.

2. Five $(14.7 \%)$ subjects reported at least one solicited AE during the study period. One subject (2.9\%) reported systemic $\mathrm{AE}$; all the others were local AEs.

3. The most commonly reported solicited $\mathrm{AE}$ by preferred term is pain at injection site (5.8\%) and itching (5.8\%).

4. Eight $(23.5 \%)$ subjects reported at least one unsolicited AEs. The most commonly reported AEs by preferred term is Inability/ functional incapacity to lift the arm (3).

5. All the reported AEs were mild or moderate in nature and were likely or unrelated to the study vaccine.

\section{REFERENCES}

[1] WHO-Immunization surveillance, assessment and monitoring-Data statistics and graphics. http://apps.who.int/immunization_monitoring/glob alsummary/timeseries/tsincidencettetanu s.html.

[2] Bruggemann H, Baumer S, Fricke WF, et al. The genome sequence of clostridium tetani, the causative agent of tetanus disease. Proc Natl Acad Sci U S A 2003;100(3):1316-21.

[3] Maternal and Neonatal Tetanus (MNT) elimination. The initiative and challenges. World Health Organization.

http://www.who.int/immunization/diseases/MNTE _initiative/en/.

[4] Gergen PJ, McQuillan GM, Kiely M, et al. A population-based serologic survey of immunity to tetanus in the United States. N Engl J Med 1995;332(12):761-6.

[5] Reid PM, Brown D, Coni N, et al. Tetanus immunisation in the elderly population. J Accid Emerg Med 1996;13(3):184-5.

[6] Ruben FL, Nagel J, Fireman P. Antitoxin responses in the elderly to tetanus-diphtheria (TD) immunisation. Am J Epidemiol 1978;108(2):145-9.

[7] Weiss BP, Strassburg MA, Feeley JC. Tetanus and diphtheria immunity in an elderly population in Los Angeles County. Am J Public Health 1983;73(7): 802-4.

[8] Middaugh JP. Side effects of diphtheria-tetanus toxoid in adults. Am J Public Health 1979;69(3): 246-9. 